Check for updates

Cite this: RSC Adv., 2021, 11, 32329

DOI: 10.1039/d1ra90150h

rsc.li/rsc-advances

\section{Retraction: Enhanced electrocatalytic activity and durability of highly monodisperse Pt@PPy-PANI nanocomposites as a novel catalyst for the electro- oxidation of methanol}

\author{
Laura Fisher
}

Retraction of 'Enhanced electrocatalytic activity and durability of highly monodisperse Pt@PPy-PANI nanocomposites as a novel catalyst for the electro-oxidation of methanol' by Özlem Karatepe et al., RSC Adv., 2016, 6, 50851-50857. DOI: 10.1039/C6RA06210E.

The Royal Society of Chemistry hereby wholly retracts this RSC Advances article due to concerns with the reliability of the data in the published article.

The two high resolution transmission electron micrograph insets in Fig. 2 that represent Pt@PPy-PANI NPs polymer composites are identical. In addition, these insets are duplicated and scaled versions of the high-resolution transmission electron micrograph insets in Fig. 1 in an International Journal of Hydrogen Energy article, ${ }^{1}$ and in Fig. 2 in a Journal of Cluster Science article, ${ }^{2}$ by the same author group representing different nanoparticles or synthetic methods. Fig. 1 in the International Journal of Hydrogen Energy article $^{1}$ represents Pt(0)/DPA@GO NPs and Fig. 2 in the Journal of Cluster Science article ${ }^{2}$ represents $\mathrm{Pt}(0) \mathrm{NPs}$. The authors claim that this was a mistake and provided replacement data for consideration. However, an expert reviewed the author's response and concluded that it did not satisfactorily address the concerns, and that the replacement figure did not fully support the conclusions. Given the significance of the concerns about the validity of the data, the findings presented in this paper are no longer reliable.

Sinan Eriş and Fatih Sen oppose this retraction. Handan Pamuk, Yunus Yıldız, Özlem Karatepe and Zeynep Dasdelen were contacted but did not respond.

Signed: Laura Fisher, Executive Editor, RSC Advances

Date: $23^{\text {rd }}$ September 2021

\title{
References
}

1 B. Çelik, G. Başkaya, H. Sert, Ö. Karatepe, E. Erken and F. Şen, Int. J. Hydrogen Energy, 2016, 41, 5661-5669.

2 E. Erken, H. Pamuk, Ö. Karatepe, G. Başkaya, H. Sert, O. M. Kalfa and F. Şen, J. Cluster Sci., 2016, $27,9-23$. 